\title{
ESTIMATING REGIONAL INPUT-OUTPUT COEFFICIENTS
}

William A. Schaffer*

Georgia Institute of Technology

Interest in constructing regional input-output models through inexpensive means has inspired frequent investigation of procedures based on national coefficients. A common criticism of models produced with "nonsurvey" techniques, which rely entirely on published data, is that they do not specifically account for imports and exports, resembling more their national counterpart than true regional models. With this criticism in mind, Teddy $T$. Su recently proposed an interesting alternative combining national coefficients and a survey of import proportions [14]. But little has been done to empirically substantiate either the arguments of the critics or the methods themselves. 1

In addition to proposing a second "semisurvey" method for constructing regional models, this paperattempts to at least partially fill the empirical void associated with both nonsurvey and semisurvey estimating techniques. Specifically, I propose to demonstrate that: 1) nonsurvey techniques for constructing regional input-output models do explicitly account for imports and exports; 2) while overestimating local interindustry relations, nonsurvey techniques still produce estimates of regional production coefficients which are closer to survey results than they are to national coefficients; 3 ) the more reasonable approach to combining minimum survey with national coefficients may be to survey exports rather than imports.

In accomplishing these tasks I will(1) review the more common nonsurvey techniques, (2) compare estimated regional input-output tables with a survey-based table for the state of Washington and with the 1958 table for the United States, (3) outline two semisurvey techniques, and(4) test these techniques using Washington data.

\section{NONSURVEY TECHNIQUES ${ }^{2}$}

As a basis for discussion, I outline four of the more common techniques for constructing regional input-output tables without direct survey. The model we examine is static, open, and descriptive. Comparing the region with the rest of the world, the model is based on a regional transactions table of the form sketched in Table 1. Given a correspondingly aggregated national transactions table and given estimates of regional outputs $\left(x_{i}\right)$ and regional final demands $\left(y_{f}\right)$, the task is to estimate regional gross flows $\left(x_{i j}\right)$, exports $\left(e_{i}\right)$, imports $\left(m_{i j}\right)$, and value added $\left(v_{j}\right)$. Or given an input-output system

$$
\sum_{j=1}^{s} A_{i j} X_{j}+\sum_{f=1}^{t} Y_{i f}+E_{i}=X_{i}(i=1,2,3, \ldots s),
$$

* The author is an Associate Professor of Economics at the Georgia Institute of Technology. The research reported here was supported in part by the Economic Development Administration, U.S. Department of Commerce (OER-163-G-67-13). He is indebted to Kong Chu, Fred A. Tarpley, Jr., and E. Malcolm Sutter, Jr., for their comments and assistance. 
and given regional outputs and demand, we derive the regional input-output system

$$
\sum_{j=1}^{s} a_{i j} x_{j}+\sum_{f=1}^{t} y_{i f}+e_{i}=x_{i}(i=1,2,3, \ldots s) .
$$

TABLE 1. SIMPLIFIED REGIONAL TRANSACTIONS TABLE

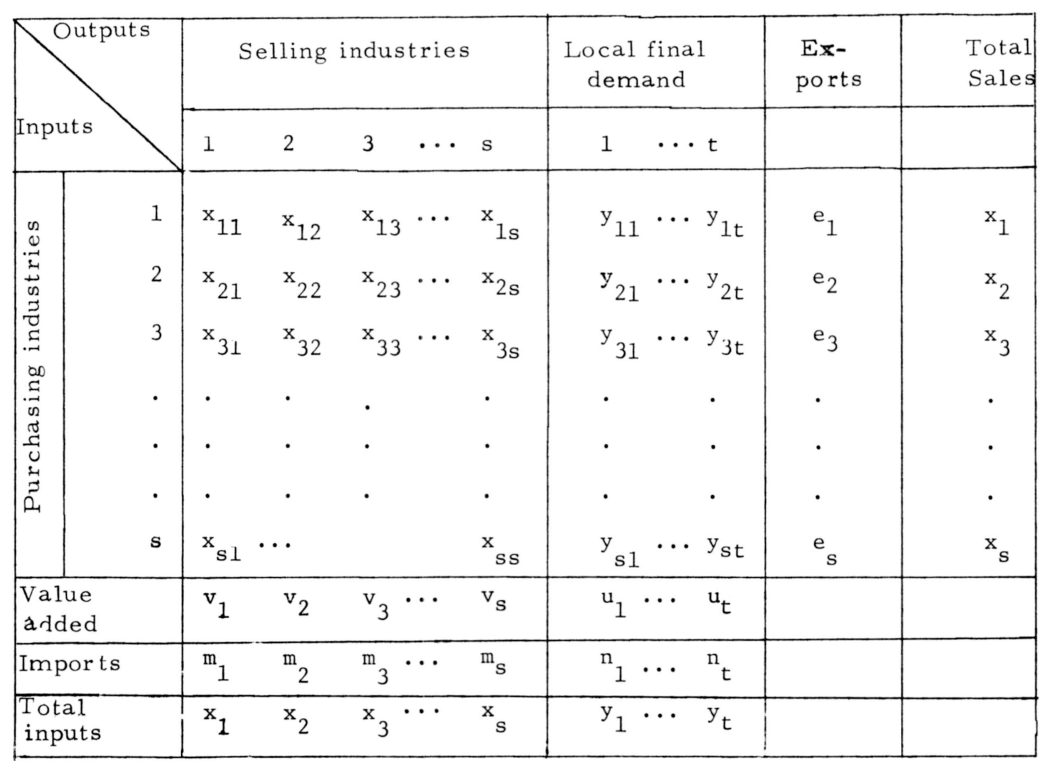

We use lower-case letters to represent variables in the regional model and upper-case letters to refer to variables in a correspondingly aggregated national model. Thus, $\mathrm{A}_{\mathrm{ij}}$ and $\mathrm{a}_{\mathrm{ij}}$ are the $\underline{\mathrm{s}} \mathrm{x} \underline{\mathrm{s}}$ production coefficients $\left(\mathrm{A}_{\mathrm{ij}}=\right.$ $\left.X_{i j} / X_{j}, a_{i j}=x_{i j} / x_{j}\right)$ in the national system and the regional system respectively, $X_{i}$ and $x_{i}$ are the outputs of industry $i, Y_{i f}$ and $Y_{i f}$ are the final demands from industry $\underline{i}$ of consuming sector $\underline{f}$, and $E_{i}$ and $e_{i}$ are exports.

Location-Quotient Procedure

A location quotient compares the relative importance of an industry in a region to its relative importance in the nation or some other base economy. In its simplest form the quotient is defined for industry $i$ as

$$
L Q_{i}=\frac{x_{i} / x}{x_{i} / x}
$$

where $x_{i}$ and $x_{i}$ are defined as before and $\underline{x}$ represents total regionaloutput and $\underline{X}$ the total national output.

A location quotient equal to one for industry i means the region is selfsufficient in this industry. A location quotient le $\bar{s} s$ than one suggests that the region imports some of its needs of output $\underline{i}$, and a quotient greater than one indicates that the region exports some of output i.

This interpretation is easily applied to determining regional input-output coefficients. If $L Q_{i}>1$, set $a_{i j}=A_{i j}$. With local final demand either given or estimated (in all of our procedures it is estimated as $\mathrm{y}_{\text {if }}=\mathrm{Y}_{\text {if }} \cdot \mathrm{x} / \mathrm{X}$ ), the exports of industry $\underline{i}$ may be computed as a residual. 
If $L Q_{.}>1$, imports are necessary, and regional production coefficients for row $\underline{i}$ are computed as $a_{i j}=L Q_{i} \cdot A_{i j}$. Imports of product $i$ are then computed as the amount necessary to satisfy production requirements.

\section{Cross-Industry Quotient Procedure}

A related approach uses what may be called the cross-industry quotient." This quotient compares the region's proportion of the national output of selling industry $i$ to that for purchasing industry $j$ :

$$
\mathrm{CIQ}_{i j}=\frac{x_{i} / x_{i}}{x_{j} / x_{j}}
$$

If $C I Q_{i j} \geq 1, a_{i j}=A_{i j}$ for cell $\mathrm{ij}$. Since the output of industry $\mathrm{i}$ is larger than that of industry $j$ in the region relative to the nation, we as sume that local industry i can prōvide all of the output required by local industry j. Regionalgross flows $\left(a_{i j} \cdot x_{j}\right)$ in this case are the local purchasing industry's share of national gross flows $\left(\mathrm{X}_{\mathrm{ij}} \cdot \mathrm{x}_{\mathrm{j}} / \mathrm{X}_{\mathrm{j}}\right)$.

If $\mathrm{CIQ}_{i j}<1, a_{i j}=\mathrm{CIQ}_{i j} \cdot \mathrm{A}_{\mathrm{ij}} \cdot$ Here regional gross flows become the local selling industry's share of national gross flows $\left(X_{i j} \cdot x_{i} / X_{i}\right)$.

As in the location-quotient technique, imports and exports are computed as remainders. If exports are negative, then balancing corrections may be necessary to construct a balanced transactions table.

\section{Supply-Demand Pool Technique}

The supply-demand pool technique derives from the concept of regional commodity balances [7]. It is also the basis for one of the more well-known nonsurvey models, the Utah model of Moore and Petersen [9].

Let $r_{i}$ be the row sum for each industry $i$ of total input requirements $\left(r_{i j}\right.$ and $c_{i f}$ ), computed from national production and consumption coefficients for each cell.

$$
\begin{aligned}
& r_{i j}=x_{j} \cdot A_{i j} \\
& c_{i f}=y_{f} \cdot \frac{Y_{i f}}{Y_{f}}
\end{aligned}
$$

Then the commodity balance $\left(b_{i}\right)$ for each industry can be computed as

$$
\mathrm{b}_{\mathrm{i}}=\mathrm{x}_{\mathrm{i}}-\mathrm{r}_{\mathrm{i}}
$$

When $b_{i}$ is positive, $a_{i j}=A_{i j}, x_{i j}=r_{i j}, y_{i f}=c_{i f}$, and $e_{i}=b_{i}$, where $e_{i}$ is exports for industry i. A positive commodity balance represents an exportable surplus.

When the commodity balance is negative, regional production coefficients are computed as proportions of the national coefficients.

$$
a_{i j}=A_{i j} \cdot \frac{x_{i}}{r_{i}}
$$

The remainder of total production requirements in each cell is imported.

This pool procedure allocates local production, whereadequate, to meet local needs; where the local output is inadequate, it allocates to each purchasing industry $j$ a share of regional output $i$ based on the needs of the purchasing industry itself relative to total needs for output $\left.\underline{i}_{\left(x_{j}\right.}=x_{i} \cdot r_{i j} / r_{i}\right)$. 
An Iterative Procedure

This last procedure not only assumes that the national production technology applies but also attempts to distribute local production according to both the national sales pattern and local needs.

Basically, we compute the required inputs $r_{i j}$ for producing estimated regional output $x_{j}$ for each industry and estimate local final demand as a proportion of national demand. If the commodity balance $b_{i}$ is positive, we follow the supply-demand poolprocedure, setting $a_{i j}=A_{i j}, x_{i j}=r_{i j}$, and $e_{i}=b_{i}$. But if $b_{i}$ is negative, we allocate local sales for each industry, basing this initial step on the national sales-distribution pattern:

$$
d_{i j}=x_{i} \cdot \frac{x_{i j}}{x_{i}} d y_{i f}=x_{i} \cdot \frac{Y_{i f}}{X_{i}}
$$

We then compare requirements andallocations to determine surplus allocations to cells $\left(z_{i j}\right)$ and construct for each industry a surplus pool available for reallocation $\left(P_{i}\right)$. If $P_{i}$ is positive, we proceed to reallocate. If $z_{i j}$ is positive or zero, regional gross flows are

$$
\begin{aligned}
& x_{i j}=r_{i j} \\
& y_{i f}=c_{i f}
\end{aligned}
$$

If $z_{i j}$ is negative, regional gross flows are

$$
x_{i j}=d_{i j}+P_{i} \cdot x_{i j} / x_{i}
$$

This step is repeated until the pool $\mathrm{P}_{\mathrm{i}}$ diminishes to 0 , spreading surplus local output among industries on the assumption that the local sales pattern tends toward the national sales pattern.

Imports are computed as described in earlier procedures.

Summary

The problem in estimating regional input-outputcoefficients is to separate the national coefficients $\left(A_{i j}\right)$ into two components: regional coefficients $\left(a_{i j}\right)$ and import coefficients $\left(m_{i j}\right)$. Contrary to commonly held opinion, ${ }^{3}$ each of the methods listed above makes a clear effort to solve this problem by estimating imports. The location quotient determines the adequacy of local production by national standards and establishes import needs in constant proportions for the appropriate rows. The cross-industry quotient is an alternative which permits variation in these import proportions within rows. The supply-demand pool technique, like the location-quotient procedure, establishes import needs in constant proportions for industries with a deficit balance of trade. The fourth procedure modifies the supply-demand pool technique to follow the national sales pattern in distributing local output before reallocating it to best satisfy local noeds.

\section{SOME EMPIRICAL TESTS}

To test the usefulness of this approach, I have simulated a $3 \hat{3}$-industry model of the state of Washington using each of the above procedures. The results of these simulations can be compared with two othermodels: the survey-based 1963 Washington study and a similarly aggregated national model. ${ }^{4}$ 
In matrix notation, we estimate a regional model

$$
\mathrm{x}=(\mathrm{I}-\mathrm{A}+\mathrm{m})^{-1} \mathrm{y}
$$

and compare it with a survey-based model

$$
x=(I-a)^{-1} y
$$

and a national model

$$
x=(I-A)^{-1} y
$$

We look at imports and exports, at regional coefficients, and at output and income multipliers. The test statistics are reported in Table 2 , around which the following discussion revolves.

\section{Imports and Exports}

Estimated imports are significant in magnitude. The iterative procedure has Washington importing 130 percent of actual survey-reported imports, while the supply-demand pool procedure leads to imports totaling 83 percent of actual imports. With a highly significant correlation between survey-based and simulated imports, each procedure yields figures reasonablyassocrated with the actual imports. But the procedures vary in their abilities to estimate values for individual industries. Regression coefficients greater than one indicate that the location-quotient and supply-demand pool procedures overestimate imports below their industry means and underestimate imports for industries above these means.

Exports tell a slightly different story. Underlying the nonsurvey techniques is an assumption of maximum local trade. This assumption is quite evident here, with no procedure estimating total exports greater than 75 percent of the survey value. While estimated and survey columns arestill highly correlated, the regression analysis indicates that the procedures severely underestimate almost all exports.

An examination of estimated exports columns (not reproduced here) reveals another critical flaw of tables based on national coefficients. Only the cross-industry quotient procedure provides an estimate of exports for each industry; the other procedures estimate exports for an industry only when the industry is large enough to supply all local needs for its products. Obviously this approach is unreasonable and shows the severity of an implicit assumption of no cross-hauling. It is just what one would expect from a purely mechanistic approach.

\section{Regional Coefficients}

Estimates yield regional input-output coefficients which on the average are substantially different from national coefficients. The ratio of total local purchases to total sales (the "weighted average total" input-output coefficient, Table 2) for the nation is 37 to 86 percent greater than the estimated ratios, while the survey is only 11 to 35 percent smaller. It seems clear that, for the matrix as a whole, the estimated coefficients must be quite different from national coefficients.

When individual columns in the interindustry matrices are compared, the results are not so clear. While statistical tests of the similarity of two columns of numbers are difficult, two rough measures have been computed: 
TABLE 2. COMPARISON OF REGIONAL INPUT-OUTPUT TABLES ESTIMATED THROUGH NONSURVEY TECHNIQUES WITH THE NATIONAL TABLE FOR 1958 AND WITH THE SURVEY-BASED TABLES FOR WASHINGTON, 1963

\section{Variable}

Imports
U.S. Washington $\underline{\text { study }}$

\section{survey}

Nonsurvey technique LQ CIQ Pool Iteration

$-$

\section{Exports}

\section{Total}

Percent of survey value Correlation

Regression constant

Regression coefficient

$\begin{array}{rrrrrr}- & 2424 & 2024 & 2278 & 2012 & 3145 \\ - & - & 83 & 94 & 83 & 130 \\ - & - & 0.76 & 0.79 & 0.75 & 0.69 \\ - & - & -10.97 & 8.82 & -5.05 & 1.81 \\ - & - & 1.38 & 0.94 & 1.29 & 0.75\end{array}$

$\begin{array}{rrrrrr}- & 3517 & 1957 & 2630 & 1971 & 1441 \\ - & - & 56 & 75 & 56 & 41 \\ - & - & 0.80 & 0.80 & 0.79 & 0.67 \\ - & - & 56.65 & 34.39 & 53.50 & 64.35 \\ - & - & 0.89 & 0.91 & 0.89 & 0.97\end{array}$

Input-output coefficients Weighted average total

Survey value as a percent National value as a percent Significant chi-square Compared with survey Compared with nation

$\begin{array}{rrrrrr}.490 & .235 & .353 & .339 & .354 & .264 \\ - & - & 67 & 69 & 66 & 89 \\ - & - & 139 & 145 & 138 & 186 \\ & & & & & \\ - & - & 5 & 0 & 4 & 7\end{array}$

Interdependence coefficients

Mean

2.01

Survey value as a percent

1.26

1.50

$1.50 \quad 1.6$

1.51

National value as a percent

Compared with survey

Correlation

Regression constant Regression coefficient

Compared with nation

Correlation

Regression constant

Regression coefficient

Simple income multipliers

Mean

Survey value as a percent

2.22

1.31

$-$$$
134
$$

77

$83 \quad 98$

$-$

$\begin{array}{llll}0.52 & 0.05 & 0.52 & 0.52\end{array}$

$-$

0.601 .20

0.58

0.60

$-$

0.44

0.04

0.45

0.50

$-$

$\begin{array}{llll}0.64 & 0.76 & 0.65 & 0.82\end{array}$

$-$

0.58

0.49

0.52

0.30

$-$

0.95

0.94

0.98

1.02

National value as a percent

Compared with survey

Correlation

Regression constant

Regression coefficient

Compared with nation

Correlation

Regression constant

Regression coefficent

\section{$-$}

(2)

$-$

$\begin{array}{llll}-\quad 82 & 76 & 81 & 95\end{array}$

$\begin{array}{rrrr}-\quad 139 & 128 & 138 & 161\end{array}$

$\begin{array}{lllll}\text { - } & 0.80 & 0.46 & 0.81 & 0.77\end{array}$

$\begin{array}{lllll}- & -0.05 & 0.12 & -0.04 & 0.04\end{array}$

$\begin{array}{lllll}- & 0.61 & 0.34 & 0.40 & 0.35\end{array}$

$\begin{array}{lllll}\text { - } & 0.43 & 0.68 & 0.44 & 0.63\end{array}$

- $\quad 6.295 .886 .275 .76$

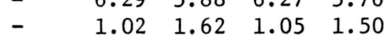




\section{NOTES FOR TABLE 2 \\ (Continued)}

The 1958 input-output table for the U.S. was aggregated in the same patterns used to perform the simulations. This aggregated table was then used to calculate the tables of direct requirements, direct and indirect requirements and simple income multipliers summarized in the column headed "U.S. study.'

The criterion value for chi-square is taken to be 18.5. Generally, the computed values of the chi-square statistic are either below the criterion or quite high.

Simple income multipliers are computed as the ratio of direct and indirect income change to direct income change in accordance with procedures described in [9] and [6].

Unless otherwise noted, correlation coefficients compare survey with simulated values and regression parameters describe a linear regression of survey on simulated values.

Sources: See footnote 4. 
chi-square statistics and correlation coefficients. 5 Using the chi-square test we have no reason to reject the hypothesis that our methods can yield production coefficients which are the same as survey-based coefficients for a total of 16 industries. Interestingly, the nonsurvey coefficients also compare favorably with the national coefficients for 16 industries, though not for the same industries nor for the same techniques as in the survey comparison.

The correlation between estimated and national coefficients is significant at the .05 level for nearly every industry and for every estimating technique. Enough coefficients remain unaltered by the estimating techniques to insure correlation. Our techniques alsoyield coefficients surprisingly close to those of the survey. Regional production coefficients a re correlated at the .05 level with survey coefficients for 26 industries in the iterative tables, for 29 in the location-quotient tables, and for 27 in the others. Given our simple aggregation with no regard for product mix and given the different populations of the nationaland state studies, our success seems remarkable.

\section{Multipliers}

Now let us look at some of the analytical results associated with our models. Output multipliers, or interdependence coefficients (sums of columns in the inverse matrix), are, on the average, much closer to survey results than to national results. Survey results range from 2 to 23 percent lower than simulated results while national output multipliers are 23 to 56 percenthigher. Both survey and national values are highly correlated (significant at the .01 level) with simulated values. But the regression parameters show that, while substantially larger in magnitude, the national output multipliers more closely parallel simulated values. On the other hand, the survey-based multipliers are underestimated at low values and overestimated at high values by the simultations.

Simple income multipliers, computed as the ratio of direct and indirect to direct income changes, show similar relations. Survey results range from 5 to 24 percent lower than simulated values while national income multipliers are 28 to 61 percent higher. The regression analysis shows that simulated values are usually much higher than survey-based income multipliers while being substantially lower than national income multipliers.

\section{Summary}

Empirically, then, at least for the state of Washington, nonsurvey methods produce regional input-output models more closely resembling surveybased regional models than their national counterpart. Imports and exports are substantial and regional production coefficients are, on the average, much lower than national coefficients. While income and output multipliers are still high compared with survey values, they are much lower than national multipliers. These analytical results, however, a re not uniform and bring into question the acceptability of the 1958 national table as a basis formechanically simulating accurate regional models. The next section explores this question further.

\section{SEMISURVEY METHODS}

This section explores the less expensive alternatives to survey-based models. These procedures are best described as "semisurvey methods". Both rely on the technology embodied in the national input-output study, but one develops an imports matrix through a survey while the other similarly derives an export vector. 
Properly done, an input-output model is constructed on the basis of a survey of industries and final consumers which documents bothpurchases and sales. That is, each respondent is first asked to designate purchases from local and nonlocal industries and payments such as wages and salaries, profits, depreciation allowances, taxes, etc. These purchases and final payments outline the "production technology" of each industry. The respondents are then asked to designate sales to local industries and to final users such as consumers, governments, and nonlocal industries. Theoretically, purchases and sales should balance when aggregated to form the regional input-output table. Actually, sampling and reporting error force the analyst to achieve balance by tediously assaying the reliability of responses and by juggling numbers until totals finally match.

One basic alternative to this full-survey approach is the "rows-only" method. First used by Hansen and Tiebout, this method assumes

...that firms know the destination of their outputs far better than the origin of their inputs, especially where regional breakdowns are required. In other words, in terms of input-output flows, information for the "rows" is easier to obtain than information for the "columns." The reason for this is that the bundle of inputs is usually so varied.and complex that their origins are difficult even for firms involved to track down accurately. However, the same firms and especially concerned with where and to whom they sell their output [4, p. 411].

The "rows-only" approach permits the analyst to avoid a complex data reconciliation. It produces only one entry per cell in the transactions table; the full-survey method forces the analyst to check his work by producing two estimates of cell values.

A second basic alternative to the full-survey approach is what could be called the "columns-only" or "purchases-only" method. This approach assumes that business firms know their sources of supply better than they do their customers. Harmston and Lund a rgue that this approach takes advantage of the detailed knowledge of expenditures required by businessmen for control and tax purchases [5, p. 67]. Producing data in the same simple form as that yielded by the rows-only method, the purchases-only approach seems particularly well-suited for use in small regions characterized by a relatively large number of locally-owned firms.

A third approach was recently introducedby Teddy T. Su. In this "imports-only" method, he suggests that we ask respondents to identify the proportion of inputs they purchase from each nonlocal industry; from these replies we construct an import-requirements matrix $(\underline{m})$ and then estimate the direct-requirements matrix for the region as $a=A-m$. As Dr. Su points out, this procedure has several advantages: it avoids the reconciliation problem, the questionnaire is easier to complete than that for a full survey, and it is more acceptable to the businessman in that he reveals onlyproportions and not absolute figures. But on the other hand, purchases appear more difficult to trace to their regional origins. It may be just as convenient to use a "columns-only" approach to estimating the a matrix, ignoring the national coefficients altogether.

If an economical survey is ourgoal and we can afford neither of the more powerful alternatives to a full survey, then I suggest that an "exports-only" survey may be more acceptable than the "imports-only" apprcach. This fourth alternative is simpler and, if Hansen and Tieboutare correct, asks questions for which more reliable answers are available. In this approach we simply canvass firms in the area, asking information on three items: their 
SIC code, value of sales for the year, and the proportion of their sales going to out-of-area purchases. The first two answers permit the analyst to classify replies and to properly weight export proportions in constructing the transactions table. This approachis simply a variant of the supply-demand pool procedure discussed above, where regional production coefficients are computed as

$$
a_{i j}=A_{i j} \cdot \frac{x_{i}-e_{i}}{r_{i}}
$$

This approach satisfies export requirements first and then allocates the remainder of local production to satisfying local needs in proportion to requirements. 6

\section{MORE TESTS}

We have simulated the 1963 Washington study using both of the above semisurvey methods and can compare these simulations with survey-based results. Table 3 reports these tests.

Imports-Only Method

The imports matrix for the Washington table is reported in sufficient detail to allow us to construct a 25-industry model. In our first attempts at implementing this method we found the simulated total flows matrix $(\mathrm{A}-\mathrm{m})$ to contain 65 negative entries, indicating that national and regional technology matrices are not identical. To obtain the most favorable results possible, these negative values were replaced by zeros. ${ }^{7}$ Further, we assumed that local final demand was as reported in the Washington study. 8 With this assumption, exports were still negative in seven out of the 25 industries. Since these estimates of exports were made merely to complete the transactions table and have no bearing on estimating regional production coefficients by the imports-only method as strictly interpreted, we made no other corrections.

The imports-only method produces a matrix of regional input-output coefficients with average values only slightly different from those of the nonsurvey inethods. Only one column in the matrix meets our chi-square criterion. The average interdependence coefficients are comparable to those of the nonsurvey techniques and are slightly better by the correlation tests. The same can be said for the income multipliers. In general, then, we canconclude that the imports-only method yields results comparable with, but not better than, the nonsurvey methods.

\section{Exports-Only Method}

With only exports and gross purchases as data from the survey-based study, we have simulated the 25-industry Washington model using the exports-only method. Only two adjustments in the supply-demand pool technique are necessary for these simulations: 1) we substitute $\left(x_{i}-e_{i}\right) / r_{i}$ for the ratio $x_{i} / r_{i}$, and 2 ) we stipulate that if $\left(x_{i}-e_{i}\right) / r_{i}$ is greater than one, then $m_{i j}$ is zero. This latter condition reduces local value added (which is computed as a residual), but this has no effect on the tests.

By the exports-only method, total imports is only slightly overestimated and industry imports seem reasonably correlated with survey-based imports. The average input-output coefficient is lower than that for all but one of the previously tested techniques. Seven columns in the input-output coefficients and income multipliers, on the average, a re closer to survey-based values than are those for all other methods except the iterative procedure. 
TABLE 3. COMPARISON OF REGIONAL INPUT-OUTPUT TABLES ESTIMATED THROUGH SEMISURVEY TECHNIQUES WITH THE SURVEY-BASED TABLES FOR WASHINGTON, 1963

$\begin{gathered}\text { Washington } \\ \text { survey }\end{gathered}$
$\underline{\text { Imports only }}$ Exports only

Imports by industries

Total
Percent of survey value
Correlation
Regression constant
Regression coefficient

$\begin{array}{crr}2424 & 2424 & 2808 \\ - & 100 & 116 \\ - & 1.00 & 0.85 \\ - & 0.00 & 19.40 \\ - & 1.00 & 0.69\end{array}$

Exports

$\begin{array}{llll}\text { Total (million of dollars) } & 3517 & -{ }^{a} & 3517\end{array}$

Input-output coefficients

Weighted average total

Survey value as a percent

Significant chi-square $\mathrm{r}^{\mathrm{b}}$

$\begin{array}{rrr}.235 & .318 & .294 \\ - & 74 & 80 \\ - & 1 & 7 \\ & & \\ 1.26 & & 1.38 \\ - & 1.50 & 91 \\ - & 84 & 0.64 \\ - & 0.71 & 0.14 \\ - & 0.29 & 0.81\end{array}$

Simple income multipliers

Average
Survey value as a percent
Correlation
Regression constant

$\begin{array}{rrr}1.31 & 1.61 & 1.47 \\ - & 81 & 89 \\ - & 0.95 & 0.78 \\ - & 0.06 & 0.01 \\ - & 1.27 & 0.90\end{array}$

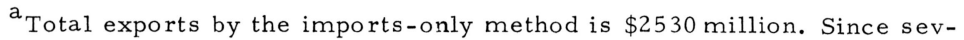
en industries have "negative exports" by this method, the number makes little sense.

${ }^{b}$ The criterion value for chi-square is taken to be 13.0. Generally, the computed values of the chi-square statistics are either below the criterion or well above it. 
While showing only slightly less significant correlation with survey-based values than for the imports-only method, these values also appear to be the best predictors of survey-based interdependence coefficients and multipliers.

\section{CONCLUSIONS}

Nonsurvey techniques for constructing regional input-output tables rely on conventional tools of economic analysis to estimate import and export patterns for regions. Mechanical in nature, they necessarily yield rough estimates. But these estimates are close enough to survey-based patterns to be reasonably realistic and are clearly distant from national values.

Tested using data from the 1963 Washington study, semisurvey methods appear to be comparable to nonsurvey techniques. The imports-only method clearly suffers from problems of industry technology and product mix but produces a matrix of input-output coefficients of about the same quality as the other methods. The exports-only method yields a balanced regional table and appears to be just superior to the other methods tested.

These methods have been tested under conditions of hardship. The 1958 input-output study, with detail for only 28 industries, does not permit the analyst to account for regional differences in product mix and is a strong handicap in simulating existing survey-basedtables. In addition, we have not taken price changes int allowed any judgment to enter into the estimating procedures.

Allowing in detail for regional peculiarities, survey-based procedures remain superior to the various estimating techniques for constructing regional models. But they a re time-consuming and expensive: Unless used by an organization capable of continuing analysis andaction, they may not be worth the effort. Perhaps the 1963 national tables, with their addedindustry detail, and a judicious use of such techniques as outlined above may permit us to construct tables which are acceptable in terms of both cost and accuracy. 


\section{FOOTNOTES}

${ }^{1}$ Earlier attempts at testing these procedures are reported in [3], [11],
and [ 12$]$.

2 This section is abstracted from [11]. This article and [12] discuss and document these and other methods and test their usefulness by simulating tables for comparison with survey-based tables for Washington, Utah, and New Mexico.

${ }^{3}$ For example, in constructing the rationale for his method of constructing regional models, Dr. Su states that other regional input-output models often ignore imports [14, p. 326]. Dr. Suqualifies this as sumption in a footnote statement. "This refers to all regional input-output models which have totally or partiallyadopted national input coefficients for an analysis of a local economy, i.e., $\underline{A}$ is interpreted as $\underline{a}$, or part of $\underline{A}$ is taken as the corresponding part of $\underline{\text { a }}$ " Suchmodels do obviously ignore imports but by common definition are not regional input-output models; rather they are what Isard might call "input-requirements models." Regional tables of this genre which reflect regional industry composition a re also discussed in [13].

Su does acknowledge the supply-demand poolapproach of Moore and Petersen but quickly dismisses it as yielding" ... derived regional coefficients ... not very different from the aggregated national coefficients. "Far from ignoring imports, this method in fact clearly develops $a_{i j}$ and $m_{i j}$ matrices. Whether the division is adequate or not is an open question which should be submitted to test.

4 The simulated models are discussed in [11] and [12]. The $1963 \mathrm{Wash}-$ ington study is reported in [1]; our comparisons are with the 33-industry model aggregated from the 59-industry tables in [2]. The simulations and aggregated national model are based on gross outputs taken from the above references and interindustry transactions from the 1958 National Input-Output Study [10].

${ }^{5}$ These tests and as sociated difficulties are discussed in [12]. Chi-square are is computed for each column as

$$
\chi_{j}^{2}=\sum_{i} \frac{\left(a_{i j} \text { base }-a_{i j} \text { survey }\right)^{2}}{a_{i j} \text { base }}
$$

The production coefficients $\left(a_{i j}\right)$ are expressed as percents to permit a uniform number of "observations ${ }^{\text {th }}$ in each case and to allow some chance of rejecting the hypothesis.

${ }^{6}$ One criticism of nonsurvey techniques noted by William $\mathrm{H}$. Miernyk is that national coefficients can be adjusted downward but not upward [8]. This criticism stems from, among other things, the fact that national coefficients showing the behavior of an aggregate industry may not reflect the upper limits for the regional input-output coefficients of a regional industry bearing the same title but differing substantially in industry or product composition. In partial correction of this flaw, the "exports-only" method permits the cofficients to be adjusted upward. In the test reported in the next section, cofficients in 4 rows are adjusted upward. Miernyk's criticism remains quite valid, especially in such mechanical simulations as reported here, where no attention has been paid to product mix. 
${ }^{7}$ Two changes in the imports matrix were also made. To better match national technology, imports of alumina were shifted from the chemicals to the nonferrous-metals industry. And to account for heavy imports of oil from foreign sources, the imports matrixwas altered such that the simulated purchases of the petroleum-refining industry from the mining industry in Washington were equal to actual purchases (zero).

${ }^{8}$ Imports to final demand are not available by importing industry in the Washington study.

${ }^{9}$ As an experiment, we didtry the imports-only method followed by proportional reductions in interindustry transactions to allow for survey-reported exports. This procedure overestimated imports by 35 percent. Since it reduces estimated total local purchases to exactly the survey-reported figure, the average interdependence coefficient (1.32) and average income multiplier (1.38) are much closer to survey results.

Other adjusting procedures could be devised. But if sufficient resources are available to acquire information on imports and on finaldemand, the analyst might as well conduct a proper survey and avoid the by-now-obvious problems of working with national coefficients. 


\section{REFERENCES}

(1) Philip J. Bourque and others, The Washington Economy: An InputOutput Study. Seattle: Graduate School of Business Administration, University of Washington, 1967.

(2) Philip J. Bourque and Eldon E. Weeks, Detailed Input-Output Tables for Washington State, 1963 (Washington Agricultural Experiment Station Circular 508, September 1969).

(3) Stanislaw Czamanski and Emil E. Malizia, "Applicability and Limitations in the Use of National Input-Output Tables for Regional Studies, "Regional Science Association Papers, XXIII (1969), 65-77.

(4) W. Lee Hansen and Charles M. Tiebout, "An Intersectorial Flows Analysis of the California Economy," The Review of Economics and Statistics, XLV (November 1963) 409-18.

(5) Floyd K. Harmston and Richard E. Lund, Application of an Input-Output Framework to a Community Economic System. Columbia: University of Missouri Press, (1967).

(6) Werner Z. Hirsch, "Interindustry Relations of a Metropolitan Area," The Review of Economics and Statistics XLI (November 1959), 360-69.

(7) Walter Isard, "Regional Commodity Balances and Interregional Commodity Flows," The American Economic Review, XLIII (May 1953), 167-80.

(8) William H. Miernyk, "Long-Range Forecasting with a Regional InputOutput Model," Western Economic Journal, VI (June 1968), 165-76.

(9) Frederick T. Moore and James W. Petersen, "Regional Analysis: An Interindustry Model of Utah," The Review of Economics and Statistics, XXXVII (November 1955), 368-83.

(10) National Economics Division Staff, "The Transactions Table of the 1958 Input-Output Study and Revised Direct and Total Requirements Data, "Survey of Current Business (September 1965), 33-49.

(11) William A. Schaffer and Kong Chu, "Nonsurvey Techniques for Constructing Regional Interindustry Models, "Regional Science Association Papers, XXXIII (1969), 83-101.

(12) William A. Schaffer and Kong Chu, "Simulating Regional Interindustry Models for Western States," Papers of the First Pacific Regional Science Conference, 1969 (Tokyo: University of Tokyo Press, 1971) 123-140.

(13) T.Y. Shen, "An Input-Output Table with Regional Weights," Regional Science Association Papers, VI (1960), 113-19.

(14) Teddy T. Su, "A Note on Regional Input-Output Models," Southern Economic Journal, XXXVI (January 1970), 325-7. 